\title{
Унифицированная серия \\ низковольтных многослойных варисторов
}

Д. махин $^{1}$, Г. Морозова ${ }^{2}$

УДК 621.382 | ВАК 05.27 .01

\begin{abstract}
Варисторы различных типов имеют широкий спектр применения в определенных областях электронных приборов и устройств. Одним из основных и наиболее важных направлений, где могут использоваться данные изделия, является защита элементов и узлов от перенапряжений в цепях постоянного, переменного и импульсного токов в составе радиоэлектронной аппаратуры. В ООО "Кулон" разрабатывается широкая унифицированная серия низковольтных многослойных варисторов различного конструктивного исполнения.
\end{abstract}

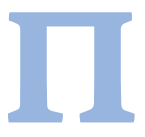

ри разработке какого-либо устройства надо быть уверенным в его надежном функционировании. Такие изделия, как варисторы, чаще всего применяются для подавления скачков напряжения в первичных цепях. Принцип достаточно прост. Варистор подсоединяется параллельно к нагрузке и при броске входного напряжения основной ток протекает через него, а не через узлы аппаратуры. В результате энергия рассеивается в виде тепла.

Варистор - электронный прибор, сопротивление которого нелинейно меняется с изменением подаваемого на него напряжения. В какой-то степени вольтамперная характеристика (BAX) похожа на ВАХ стабилитрона. Варистор является изделием многократного использования, как и стабилитрон, но по сравнению с ним значительно быстрее восстанавливает свое высокое сопротивление после снятия напряжения.

Также варистор имеет ряд достоинств по сравнению с газоразрядными приборами:

- более широкий диапазон рабочих напряжений (от единиц до сотен вольт);

- большее быстродействие;

- более низкая стоимость.

Основные параметры варисторов:

- классификационное напряжение $\left(U_{n}\right.$ от 4 до 68 B);

- максимально допустимое действующее переменное напряжение;

- номинальная средняя рассеиваемая мощность;
- максимальный постоянный или переменный рабочий ток (Iр от 0,03 до 0,1 мА);

- максимальный импульсныйток ( $\mathrm{I}_{\text {рр }}$ от 30 до 1200 А при длительности 8-20 мКс).

Технологии изготовления. Варистор, в основном, состоит из оксида цинка (ZnO) с небольшим содержанием висмута, кобальта, магния и других элементов. Изделие на основе оксида металла спекается в процессе изготовления в керамический полупроводник с кристаллической решеткой, которая и позволяет рассеивать очень большие энергии. Конструкция варистора представляет собой изотропную гранулярную структуру оксида цинка. Граница разделения гранул структуры напоминает ВАX p-n-перехода в полупроводниках.

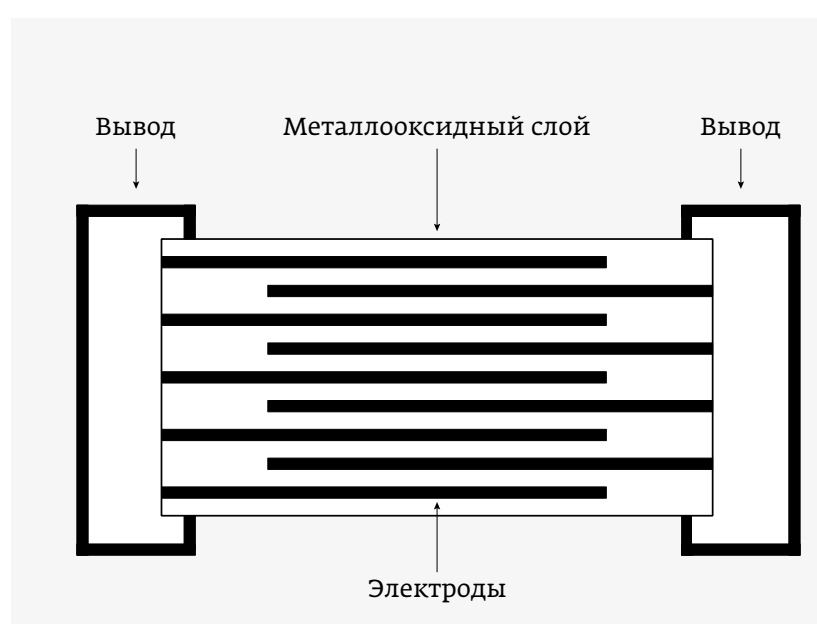

Рис. 1. Структурная схема многослойного варистора 


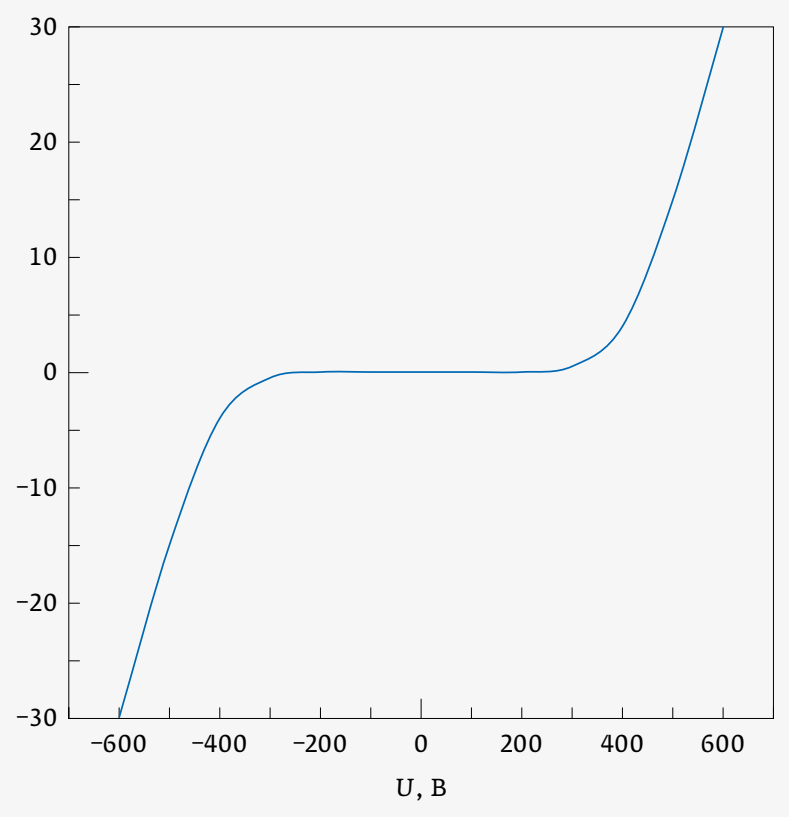

Рис. 2. Вольтамперная характеристика варистора

Изготовление многослойных варисторов складывается из ряда технологических этапов:

- подготовки материалов (проверка химического состава, измельчение, перемешивание до получения однородной смеси);

- получения пленки ZnO (полученная ранее смесь раскатывается в листы);

- нанесения пасты Ag/Pd (из металлизированных слоев формируется сборка);

- прессования пакета (многослойная структура подвергается прессованию под давлением);

- резки (полученная структура разрезается на отдельные части в соответствии с габаритными размерами изделия, проверка совмещения металлизированных слоев);

- обжига (данная операция требуется для снижения механических напряжений структуры и создания p-n-переходов, обеспечивающих необходимую ВАХ варистора);

- формирования внешних электродов (торцевые контакты изготавливаются путем

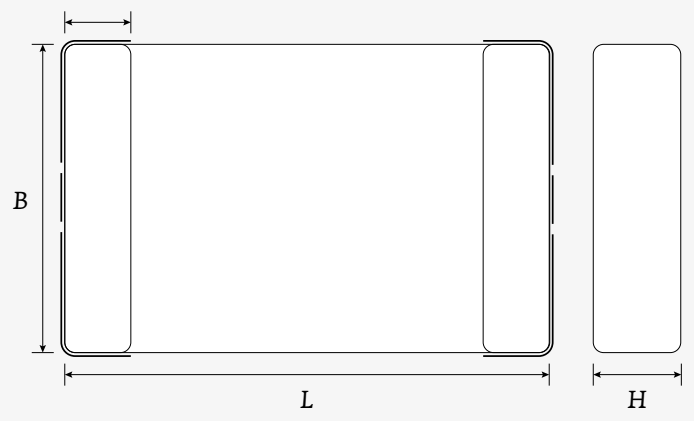

Рис. 3. Общий вид варистора ВР-18

нанесения пасты Ag/Pd, на которой в дальнейшем формируются внешние электроды Ni / Sn);

- выходного контроля (проверка электрических параметров, способности к пайке).

Данная технология имеет ряд преимуществ. При изменении толщины ZnO, можно получить большие значения пробивного напряжения, чем толще слой, тем больше пробивное напряжение варистора. Так как структура является симметричной, то полярность прикладываемого напряжения не имеет значения, что обеспечивает симметричность вольтамперной характеристики.

В тот момент, когда в цепи появляется скачок напряжения, сопротивление варистора уменьшается во множество раз, уменьшая импульс напряжения до

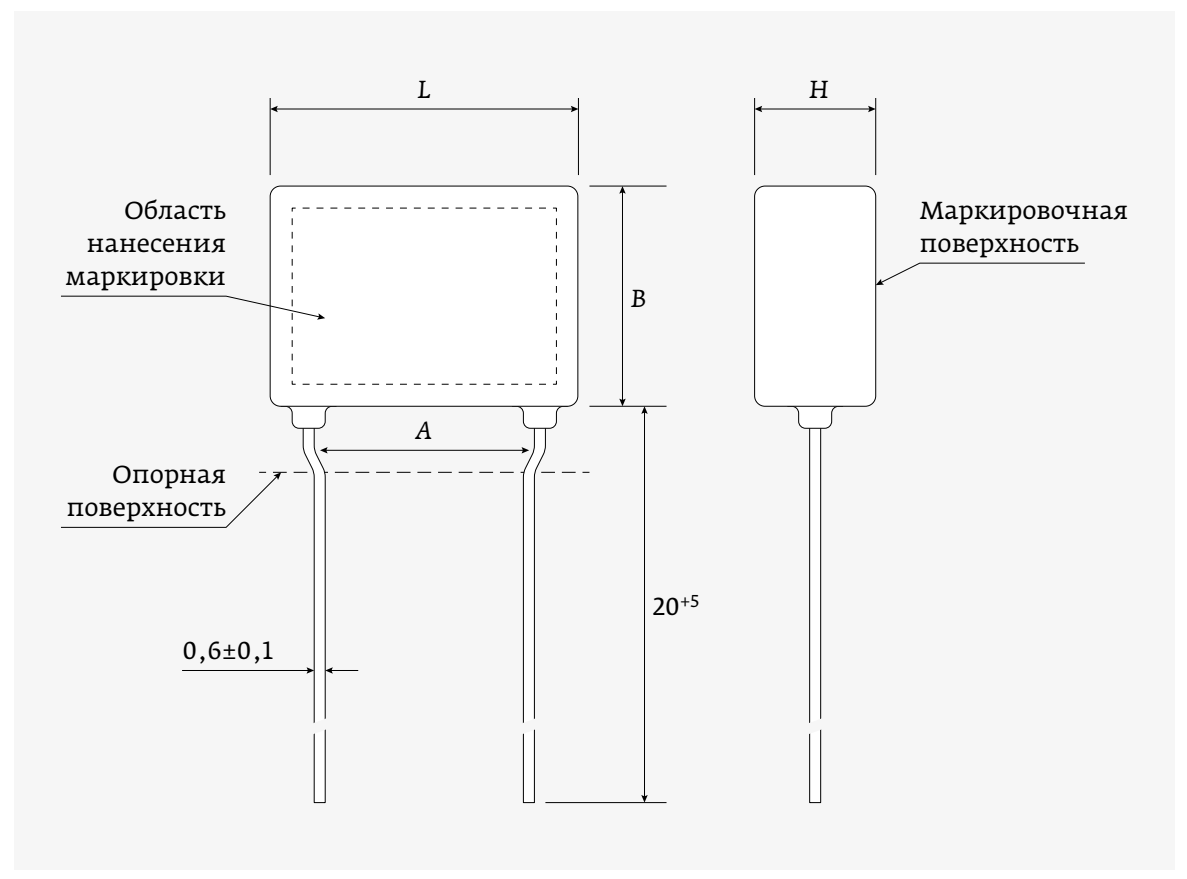

Рис. 4. Общий вид варистора ВР-19 
Таблица 1. Классификационное напряжение варисторов ВР-18, ВР-19

\begin{tabular}{|c|c|c|c|}
\hline \multirow{2}{*}{\multicolumn{2}{|c|}{$\begin{array}{c}\text { Условное } \\
\text { обозначение } \\
\text { (типономинал) }\end{array}$}} & \multicolumn{2}{|c|}{ Норма параметра } \\
\hline & & Классификационное & Допускаемое отклоне- \\
\hline BP-18-04 & BP-19-04 & 4 & \multirow{6}{*}{ \pm 20} \\
\hline BP-18-08 & BP-19-08 & 8 & \\
\hline BP-18-11 & BP-19-11 & 11 & \\
\hline BP-18-12 & BP-19-12 & 12 & \\
\hline BP-18-15 & BP-19-15 & 15 & \\
\hline BP-18-18 & BP-19-18 & 18 & \\
\hline BP-18-22 & BP-19-22 & 22 & \multirow{8}{*}{ \pm 10} \\
\hline BP-18-24 & BP-19-24 & 24 & \\
\hline BP-18-27 & BP-19-27 & 27 & \\
\hline BP-18-33 & BP-19-33 & 33 & \\
\hline BP-18-39 & BP-19-39 & 39 & \\
\hline BP-18-47 & BP-19-47 & 47 & \\
\hline BP-18-56 & BP-19-56 & 56 & \\
\hline BP-18-68 & BP-19-68 & 68 & \\
\hline
\end{tabular}

безопасного для цепи значения. Так как количество гранул в структуре варистора очень большое, то поглощаемая варистором энергия может достигать намного бо́льших значений по сравнению с единичным p-n-переходом в стабилитронах.

В связи с растущей тенденцией замены импортных комплектующих на отечественные компоненты, возникла необходимость разработки варисторов как для поверхностного, так и для навесного монтажа.

Варисторы ВР-18 - прямоугольные, без выводов, незащищенные, неизолированные, с лужеными контактными площадками (рис. 3).

Варисторы ВР-19 - защищенные, неизолированные, с двумя проволочными лужеными однонаправленными выводами (рис. 4)

Как отмечалось ранее, одним из основных параметров варистора является классификационное напряжение. Это напряжение при определенном токе. В нашем случае при токе 1 мА. Значения данных параметров для изделий ВР-18 и ВР-19 представлены в табл. 1.

Планируемый срок начала серийного производства - второй квартал 2020 года.

\section{КНИГИ ИЗДАТЕЛЬСТВА "ТЕХНОСФЕРА»}

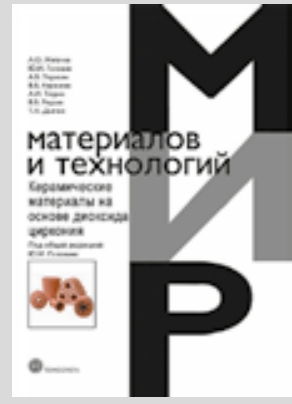

Цена 760 руб.

\section{КЕРАМИЧЕСКИЕ МАТЕРИАЛЫ} НА ОСНОВЕ ДИОКСИДА ЦИРКОНИЯ

\section{Жигачев А. О., Головин Ю. И., Умрихин А. В., Коренков В. В., Тюрин А. И.,} Родаев В. В., Дьячек Т. А.

Под общей редакцией Ю. И. Головина

В книге обобщены данные по возможному химическому составу, кристаллической и микроструктуре, а также свойствам керамических материалов на основе диоксида циркония. Рассмотрены наиболее развитые технологии получения этих керамик и композитов на их основе. Монография состоит из четырех частей, каждая из которых освещает определенную область вопроСов, связанных с керамическими материалами.

Книга будет интересна широкому кругу читателей: от студентов естественно-научных специальностей до инженеров, технологов и медицинских работников, связанных с практическим применением циркониевой керамики.

Разработка методов синтеза, получение и подготовка оригинальных керамических образцов на основе бадделеита выполнены при поддержке гранта Российского научного фонда (проект № 16-19-10405). Отработка методик исследования и определение физико-механических характеристик осуществлены при поддержке гранта Министерства образования и науки Российской Федерации (проект № 16.2100.2017/ПЧ). 
